\title{
Ionic Strength and Drag Reduction of Polymers in Straight Pipes - An Experimental Investigation
}

\author{
Ahmed Kamel \\ College of Engineering, The University of Texas Permian Basin, Odessa, TX, USA \\ Correspondence: Ahmed Kamel, College of Engineering, The University of Texas Permian Basin, 11105 W. Highway \\ 191, Midland, TX 79705. Tel: 1-432-552-345 E-mail: kmel_a@utpb.edu
}

Received: January 27, 2021

Accepted: March 4, $2021 \quad$ Online Published: May 22, 2021

doi:10.5539/esr.v10n2p23

URL: https://doi.org/10.5539/esr.v10n2p23

\begin{abstract}
Previous work has tied the drag reduction properties of polymer solutions to type and concentration of salts, rather than its ionic strength, although it is a more extensive parameter to investigate the effects of salt contents on fluids behavior. The current study aims at investigating the relationship between ionic strength and drag reduction characteristics of polymer solutions when flowing in straight tubing.

Nalco ASP-700 and ASP-820, two common anionic AMPS copolymers, are examined with various salts $(2 \% \mathrm{KCl}, 4 \%$ $\mathrm{KCl}$, and synthetic seawater). Flow tests were conducted using a small-scale flow loop that includes a straight tubing with an outside diameter of $1.27 \mathrm{~cm}$ and a length of $4.57 \mathrm{~m}$.

It has been found that drag reduction performance of polymer solutions is well correlated with ionic strength, rather than salt type and/or concentration. With high ionic strength, lower drag reduction is noticed despite of the reduced salt concentration. Nevertheless, at higher Reynolds number, the effects of ionic strength minimizes. Both polymer solutions exhibit effective drag reduction characteristics and their behavior is greatly affected by polymer type, shear rate, and salt content. Correlations, with acceptable confidence level, between drag reduction ratio and solutions ionic strength are proposed. The correlations are strongly recommended to investigate the effects of salt types and/or concentrations, represented by its ionic strength on drag reduction behavior of polymer solutions in straight tubing.
\end{abstract}

Keywords: Ionic strength, drag reduction, salt, polymers, straight pipes

\section{Introduction}

Discovered more than 60 years ago, Toms effect (Toms 1949) or drag reduction is a turbulent flow phenomenon where frictional pressure losses can be reduced drastically by adding a minute amount of high-molecular weight components such as polymers and surfactants. They are known to lower the friction pressure losses up to $80 \%$ over the base solvent (Savins 1964; Lumely 1973). The drag reduction concept can be used to reduce system friction pressure losses at certain flow rates, maximize flow rates at certain pumping pressures, reduce pipe and pump size, increase system length, decrease heat transfer, or a combination thereof (Berman 1978; Gasljevic and Matthys 1996).

Since the discovery of drag reduction phenomenon in pipe flow, there have been numerous extensive studies and reviews on drag reduction, its mechanism, and the factors affecting it. However, drag reduction is still a mystery and not well understood. This is because drag reduction phenomenon includes the interaction of two fields; neither of the two is well understood. The first field is turbulence (Lesieur 1989) and the second one is the interaction of additives with turbulence (Bewersdorff and Berman 1988; Sung et al. 2004).

It has been known that drag reducing solutions are very sensitive to shear intensity and duration, drag reducers concentration, molecular weight and distribution, molecular conformation, solvent chemistry, $\mathrm{pH}$, temperature, and salinity (Brunn 1987). In addition, other pipe-related factors can have significant effects on drag reduction phenomenon such as pipe diameter, pipe roughness, and pipe geometry. Despite the extensive application of brine solutions as base fluid, salinity effects on drag reduction characteristics have received a minimal attention (Kamel and Shah 2009).

Drag reduction characteristics and rheological behavior of these drag-reducing solutions are very sensitive to the nature and structure of added salts. Most studies of the effect of salinity on drag reduction were traditionally conducted using Sodium Chloride, $\mathrm{NaCl}$ and the effects were attributed to the changes in shear viscosity (Hong et al. 2015). Kamel and Shah (2009), for example, investigated the effect of two different salt solutions $(2 \% \mathrm{KCl}$ and synthetic seawater) on drag reduction characteristic of two anionic polymers (ASP-820 and ASP-700) in straight tubing. Shah and Vyas (2011) repeated the study in coiled tubing. The developed correlations in both studies used salt concentration (Cs) to quantify the 
salt effects on drag reduction behavior. Other studies expressed the salt concentration in ppm (Al-Yaari et al 2013, Hassiba and Amani, 2013). Overall, salt concentration (as percentage, \%, or ppm) has been customarily used to quantify the salt effects on drag reduction. No studies have ever considered the ionic strength of salt solution. Different salt types yield different ionic strength, even with the same concentration. Therefore, the aim of the present study is to experimentally investigate the correlation between ionic strength and drag reduction of polymeric solutions flowing in straight tubing.

\section{Method}

\subsection{Flow Loop}

The flow loop used in this investigation includes tanks for mixing and storage and a centrifugal pump to feed the Moyno pump. Moyno pump is used to circulate the test fluid in a $1.27 \mathrm{~cm}$ (smooth straight pipe with an inside diameter of $1.1 \mathrm{~cm}$ and a length of $4.57 \mathrm{~m}$. (0.91 m as an entrance length and $0.6 \mathrm{~m}$ as an exit length). Differential pressure sensors are used to measure the frictional pressure losses while a Micromotion sensor measures flow rate, fluid density, and fluid temperature. The collected data is transmitted via wireless system to a personal computer (Kamel and Shah 2009).

\subsection{Fluids}

Two high molecular weight, anionic, polyacrylamide copolymers, Nalco ASP-700 and ASP-820, are used at their optimum concentration, i.e. 0.07 vol. \% (Shah and Kamel 2010). The two polymers are mixed with four different base fluids; fresh water, $2 \% \mathrm{KCl}$ brine, $4 \% \mathrm{KCl}$ brine, and synthetic seawater. For synthetic seawater, different recipes exist. The recipe adopted includes $2.85 \mathrm{~g} / \mathrm{l}$. Na $2 \mathrm{SO}_{4}, 29.96 \mathrm{~g} / \mathrm{l} \mathrm{NaCl}$, and $1.14 \mathrm{~g} / \mathrm{l} \mathrm{CaCl}_{2}$ to mimic real environmental conditions. This is equivalent to a total dissolved salt (TDS) of $3.4 \%$.

\subsection{Ionic Strength}

The ionic strength of a solution measures the total ion concentration in that solution (Lewis and Randall 1921). It represents the interactions of ions with water molecules as well as other ions in the solution. Ions with more charge are counted more due to stronger electrostatic interactions with other ions. The ionic strength affects the ion activity and it is function of the concentration of all the ions, molality, and their mean charge density, which is based on the electro-neutrality condition for solutions. When the ions are of the same sign, an increase in the ionic strength increases the reaction rate. On the contrary, when ions of opposite signs react, there is a decrease in the reaction rate with increasing ionic strength. For example, the ionic strength of seawater is about 500 times larger than that of fresh water (Sastre de Vicente 2004). Mathematically, it can be calculated using the following formula:

$$
I=\frac{1}{2} \sum_{i} m_{i} z_{i}^{2}
$$

where $m_{i}$ and $z_{i}$ are the molality and charge, respectively, of each ionic species.

\subsection{Test Procedure}

In preparing the test fluid, the mixing procedure recommended by the product provider was followed to ensure full hydration. The polymer at the desired concentration was first mixed with 3 liters of fresh water in a laboratory blender and then allowed to hydrate for 10 minutes. The fully hydrated, pre-mixed polymer was then added to the base fluid while operating the mixer at a moderate speed. To attempt to avoid any excessive shear effects, all fluids were circulated in a single-pass mode at the room temperature. When circulating the test fluid, flow rate was set at a desired value and the steady-state pressure drop across the $10 \mathrm{ft}$. straight pipe was recorded. The flow rate was then, increased and the corresponding pressure drop was noted. At each flow rate, adequate time was allowed for the fluid to achieve steady-state conditions.

Before and after the test, base fluid was circulated in the flow loop for calibration, accuracy, and reproducibility. In addition, fluid samples were collected before and after each test for viscosity measurement and any possible shear degradation effects.

The collected data includes flow rate, differential pressure drop across the $10 \mathrm{ft}$. straight pipe, fluid density, and temperature. In the analysis, data was converted into the famous dimensionless numbers, Fanning friction factor, $f$ and solvent Reynolds number, $N_{R e s}$. The percent drag reduction, $D R$ and drag reduction ratio, $D R R$ were calculated using the following equations.

$$
\begin{gathered}
D R=1-\frac{f_{t}}{f_{s}} \\
D R R=\frac{D R_{s}}{D R_{o}}
\end{gathered}
$$

Both $D R$ and $D R R$ are plotted against solvent Reynolds number, $N_{R e s}\left(=\rho_{s} v d / \mu_{s}\right)$. 


\section{Results}

To calibrate the flow loop and check its accuracy, flow tests using water were conducted. Data from these water tests was compared with predictions from Drew Correlation (Drew et al. 1932) and a reasonable agreement was noticed with an average deviation less than $2 \%$ and a maximum deviation less than $3 \%$ indicating the system accuracy and data reproducibility (Shah and Kamel 2010).

\subsection{Density and Viscosity}

The test fluid density and viscosity (measured using A Cannon- Fenske Capillary Viscometer) are summarized in Table 1. As it can be seen, viscosity decreases as the ionic strength increases. However, the $4 \% \mathrm{KCl}$ solution, with an ionic strength as double as the $2 \% \mathrm{KCl}$ solution, does not yield the same effect on fluid viscosity as it changes only from 1.53 cP to $1.44 \mathrm{cP}$. In addition, ASP-700 yields higher viscosity fluids compared to ASP-820. This is mainly due to the difference between the two polymers syntheses, molecular weight, and molecular structure.

Table 1. Characteristics of Test Fluids

\begin{tabular}{l|lll|l}
\hline & & Density, ppg & Absolute Viscosity, cP & $\begin{array}{l}\text { Ionic } \\
\text { Strength }\end{array}$ \\
\hline Base Fluid & Fresh Water & 8.34 & 1.093 & 0.0015 \\
\hline & Fresh Water & 8.34 & 2.96 & 0.0015 \\
ASP-700 (0.07\% vol.) & $2 \% \mathrm{KCl}$ & 8.36 & 1.53 & 0.27 \\
& $4 \% \mathrm{KCl}$ & 8.38 & 1.44 & 0.53 \\
& Synthetic Seawater & 8.43 & 1.35 & 0.60 \\
\hline \multirow{3}{*}{ ASP-820 (0.07\% vol.) } & Fresh Water & 8.34 & 2.28 & 0.00125 \\
& 2\% KCl & 8.36 & 1.30 & 0.27 \\
& Sycl KCl & 8.38 & 1.26 & 0.53 \\
\hline
\end{tabular}

\subsection{Drag Reduction Characteristics}

Effect of ionic strength on drag reduction characteristics of both polymers is significant as it can be seen in Fig. 1 and 2 . Drag reduction values for both polymers in $2 \% \mathrm{KCl}$ solution with 0.27 ionic strength are much reduced than the values for fresh water solution with 0.0015 ionic strength. Increasing the ionic strength by adding more $\mathrm{KCl}$ and/or other salts reduces the drag reduction values even more. Synthetic seawater solutions with the highest ionic strength of 0.6 yields the lowest drag reduction values.

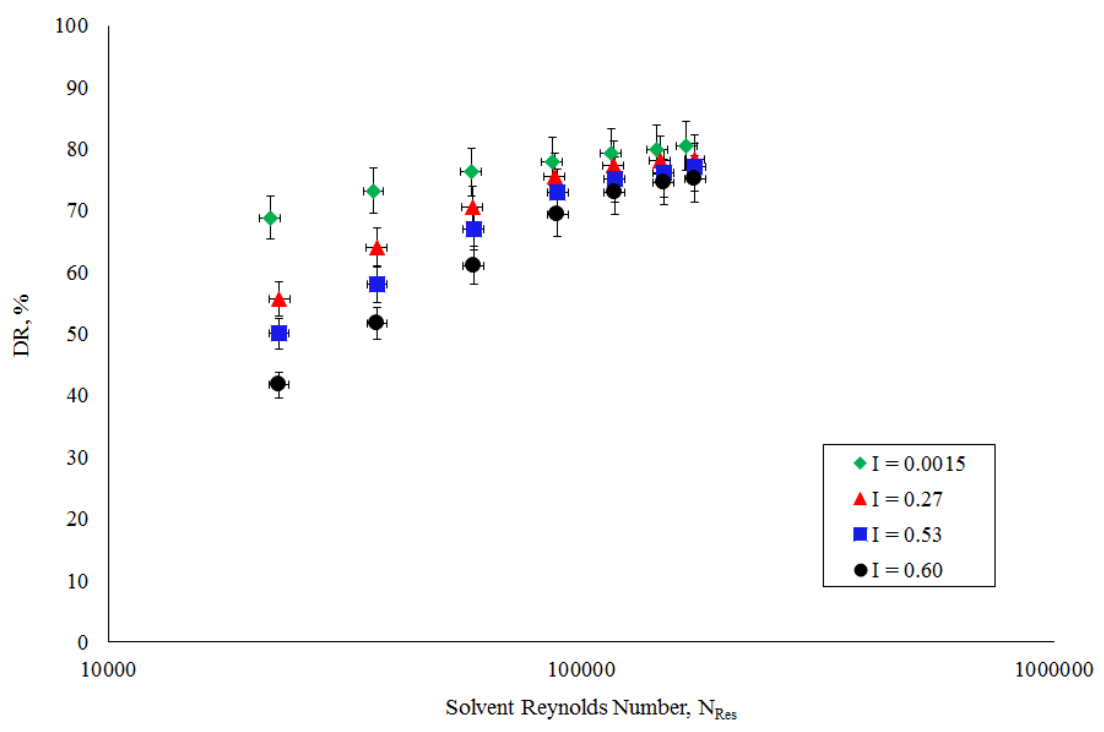

Figure 1. Drag Reduction vs. Reynolds Number for ASP-700 Polymer 
Another important note is that increasing flow rate helps reduce the detrimental effects of ionic strength as the data lines approach each other. The difference diminishes as the Reynolds number increases. At low Reynolds number, the effects of ionic strength are significant where the drag reduction values reduce dramatically from $69 \%$ for fresh water solutions, lowest ionic strength to about $42 \%$ for synthetic seawater, the highest ionic strength. On the other hand, at high Reynolds number, the values are $80 \%$ and $75 \%$ for the lowest and the highest ionic strength solutions, respectively. For the solutions with 0.27 and 0.53 ionic strength, drag reduction values are reasonably intermediary.

As noticed with viscosity data, doubling the ionic strength does not result in the same effect in dropping the drag reduction values. The drag reduction values for 0.27 ionic strength solution are not twice the values for 0.53 ionic strength solution. Furthermore, at high Reynolds number, the difference is even minimal. However, one should notice the difference between the investigated polymers regarding their drag reduction characteristics and their response to variance in the solution ionic strength.

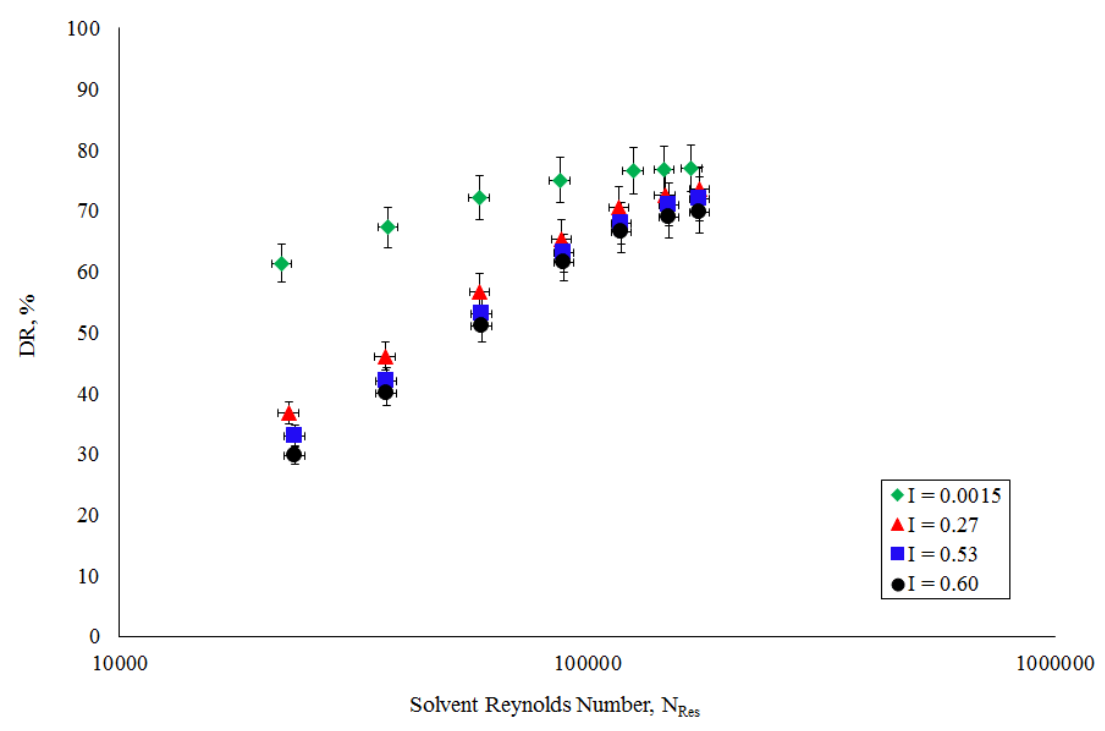

Figure 2. Drag Reduction vs. Reynolds Number for ASP-820 Polymer

Same conclusions can be drawn from Fig. 3 and 4, which show the drag reduction ratio, DRR as a function of solvent Reynolds number. DRR is significantly affected by the ionic strength changes, especially at low Reynolds numbers. As the Reynolds number increases, the difference diminishes. Different behavior of both polymers is, likewise, clear.

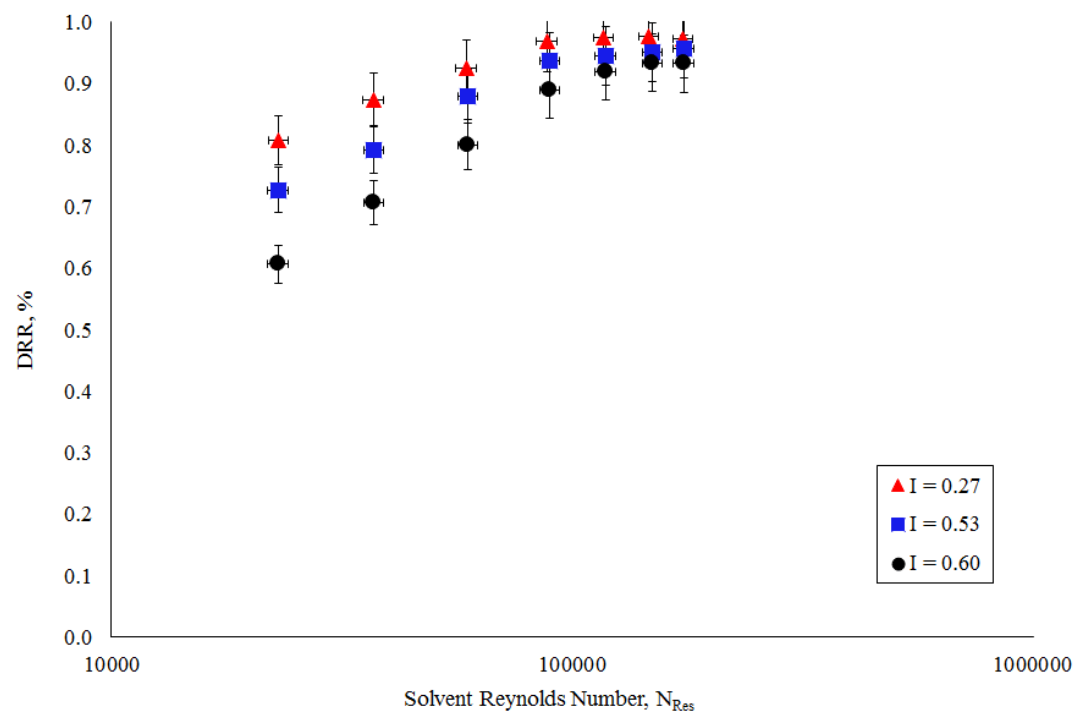

Figure 3. Effect of Ionic Strength on Drag Reduction Ratio of ASP-700 Polymer 


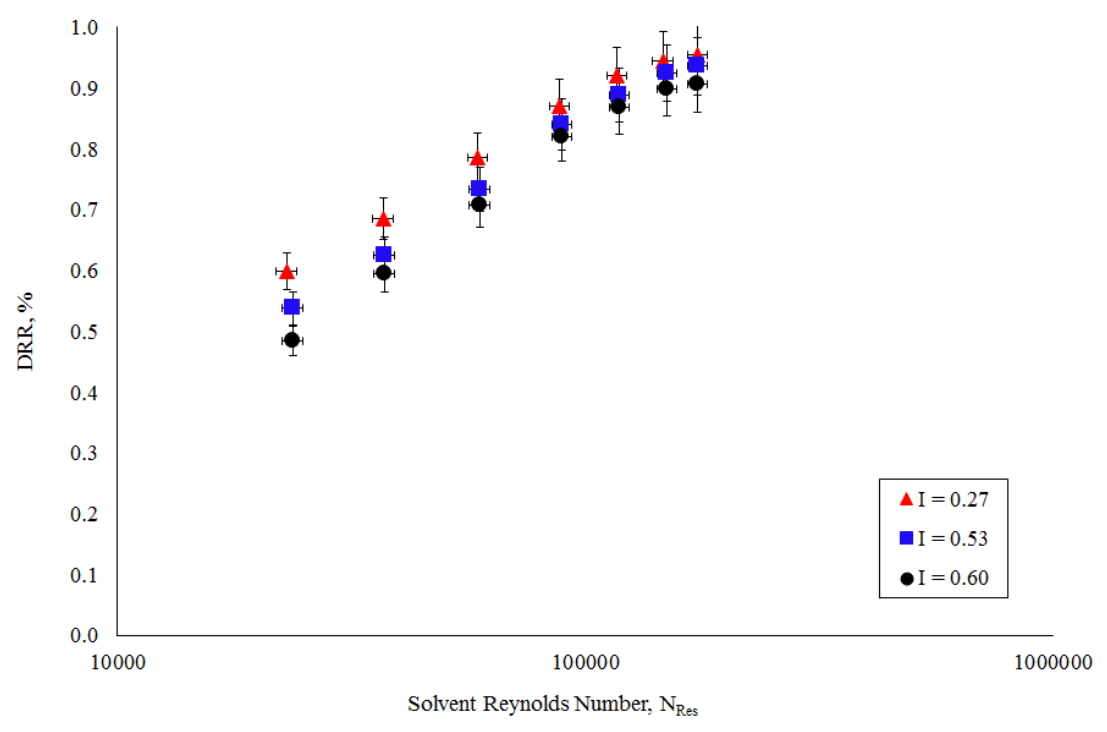

Figure 4. Effect of Ionic Strength on Drag Reduction Ratio of ASP-820 Polymer

\subsection{Onset of Drag Reduction}

To investigate the onset of drag reduction, Virk's (Virk 1975) drag reduction envelope is considered. It is designed using Prandtl-Karman coordinates and has three boundaries; Poiseuille's Law for laminar flow, Prandtl-Karman Law for turbulent flow with zero drag reduction and Maximum Drag Reduction Asymptote, an asymptotic regime of the maximum possible drag reduction. The significance of the drag reduction envelope is presented elsewhere (Shah and Kamel 2010). Fig. 5 and 6 show the drag reduction envelope for both ASP-700 and ASP-820 polymeric solutions, respectively.

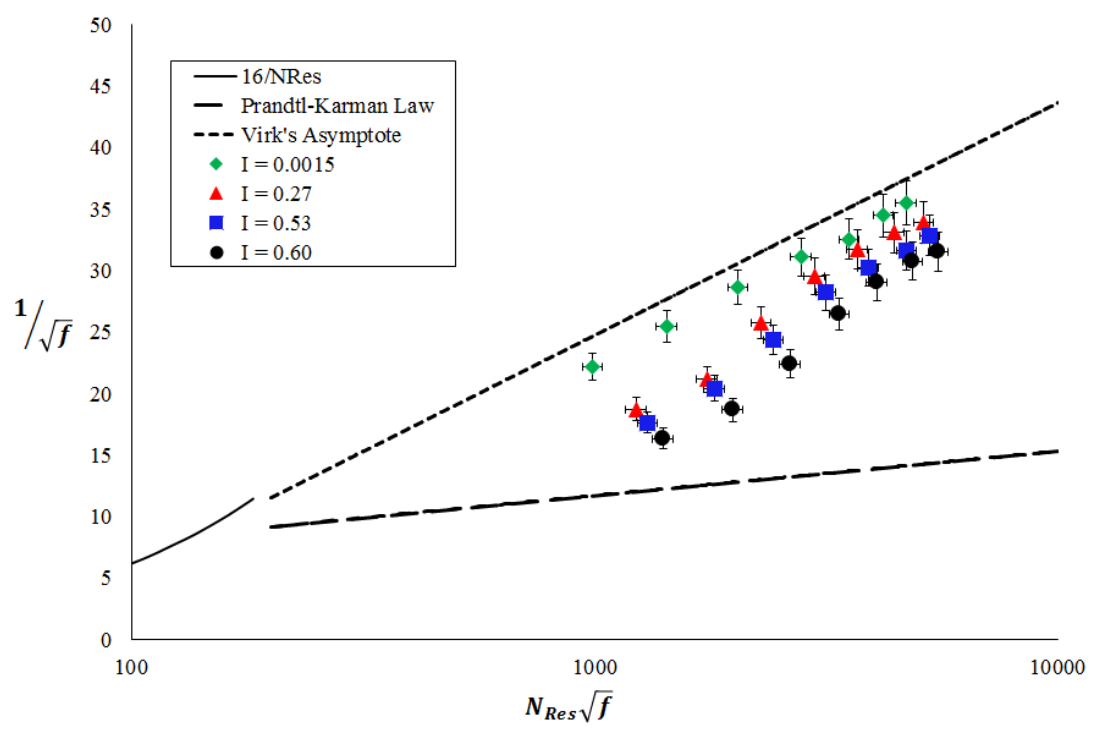

Figure 5. Drag Reduction Envelope for ASP-700 Polymer

It can be seen from Fig. 5 and 6 that, data lie between zero-drag reduction and the maximum-drag reduction lines. The effect of ionic strength on the onset of drag reduction is very clear. Considering the intersection points between the extrapolated data lines and the corresponding base line, it can be said that, adding $\mathrm{KCl}$ and/or other salts, i.e. increasing ionic strength, delays the onset of drag reduction. Drag reduction with low ionic strength solutions occurs earlier compared to high ionic strength solution. Increasing water salinity delays drag reduction further. For example, drag reduction in fresh water solution occurs much earlier $\left(N_{\text {Res }} \sqrt{f}=250\right)$ compared to $2 \% \mathrm{KCl}$ solution $\left(N_{\text {Res }} \sqrt{f}=700\right)$ for ASP-700 polymer. For ASP-820 polymer, the values are 500 and 900, respectively. 


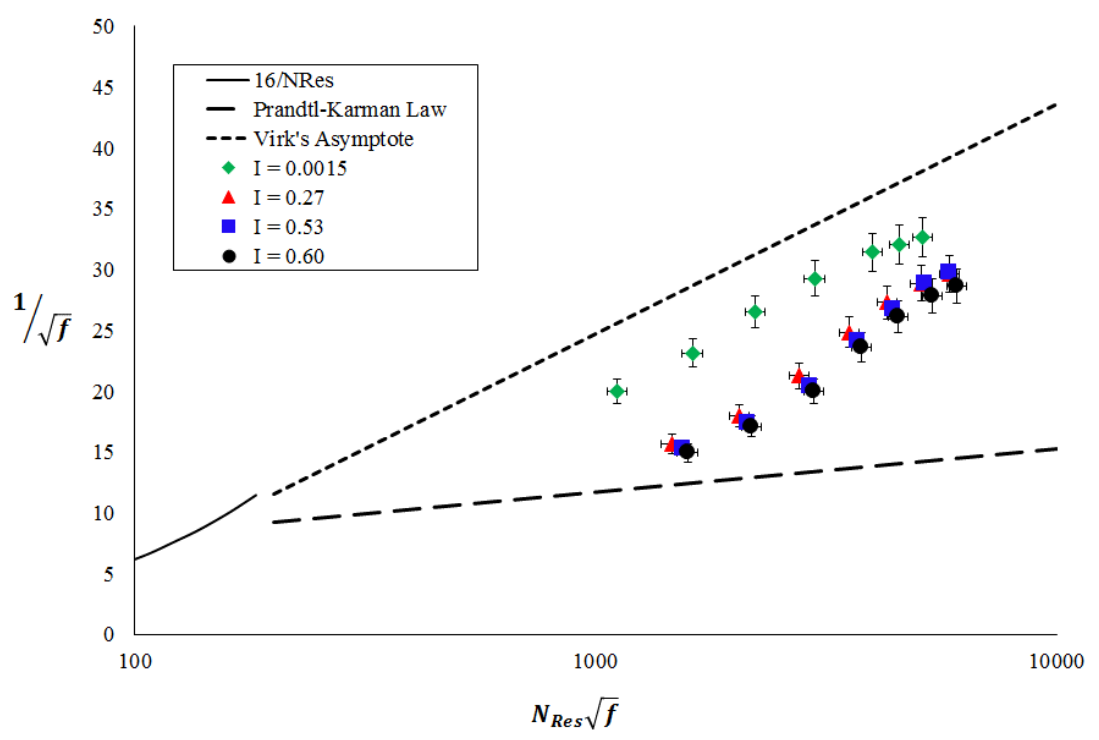

Figure 6. Drag Reduction Envelope for ASP-820 Polymer

In addition, as it can be seen in both figures, all data lines have slopes higher than those for the bottom baseline. This indicates that no further drag reduction can be obtained by increasing polymer concentration (optimum concentration is adopted) and increasing shear rate is the only way to increase drag reduction, as implied from the drag reduction envelope (Shah and Kamel 2010). Again, the difference between both polymers is obvious. In general, conclusions from drag reduction envelopes agree with the conclusions drawn in the previous sections.

\subsection{Development of Correlations}

The data gathered was used to develop a correlation to predict drag reduction ratio as a function of both solvent Reynolds number, $N_{\text {Res }}$ and solution ionic strength, I. Unfortunately, a single correlation for both polymer was not possible due to their different behaviors. Therefore, two separate correlations are proposed.

ASP-700

$$
D R R, \%=\left[-3.2915 \times I^{2}+2.0952 \times I-0.0003\right] N_{R e s}^{\left(2.8475 \times I^{2}-2.1034 \times I+0.4535\right)}
$$

ASP-820

$$
D R R, \%=\left[-0.1475 \times I^{2}+0.0196 \times I+0.062\right] N_{\text {Res }}^{\left(0.8428 \times I^{2}-0.4881 \times I+0.3079\right)}
$$

The above two correlations are valid to predict DRR for polymers flowing in smooth pipes at their optimum concentration over a wide range of solvent Reynolds number $\left(20,000<N_{R e s}<200,000\right]$ and ionic strength $(0.0015<\mathrm{I}<$ 0.6). A comparative cross-plot between the predicted and measured DRR is shown in Fig. 7 for ASP-700 polymer and in Fig. 8 for ASP-820 polymer.

The comparison shows a reasonable agreement between the measured and predicted data with an average deviation of $2.1 \%$ and a maximum deviation of $3.3 \%$ for ASP-700 polymer and an average deviation of $2.5 \%$ and a maximum deviation of 3.9\% for ASP- 820 polymer. This confirms the validity of the proposed two correlations and ensures their high accuracy. Nevertheless, tests with different salt types and concentrations are highly recommended. In addition, the above two equations are recommended to be examined versus experimental data gathered using large-scale flow loops. In general, slick-water fracture treatments are characterized by reduced gel damage, limited height growth, enhanced long-term production, and reduced job cost (Liu et al., 2006). With the global trend of using small diameter tubing, drag reduction concepts allows pumping the slick-water at rates high enough to condition the fracture dimensions and avoid screen-out. In special brine slick-water applications, the proposed correlations are necessary to precisely predict the drag reduction behavior of slick-water and better design the treatment hydraulics. 


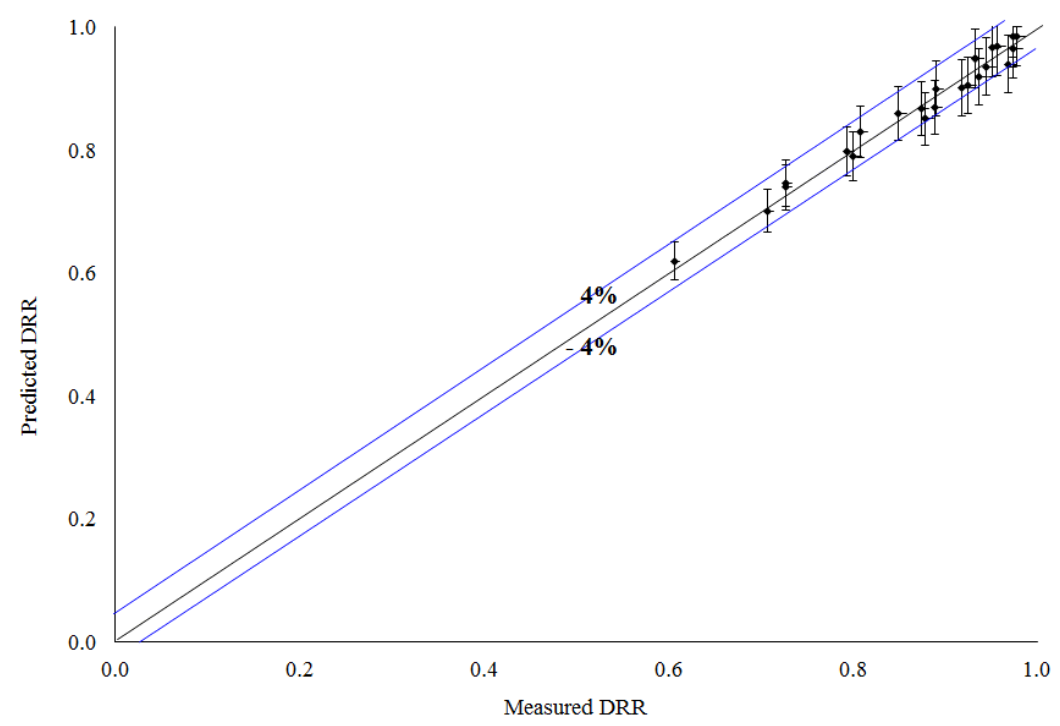

Figure 7. Cross Plot between Measured and Predicted DRR for ASP-700

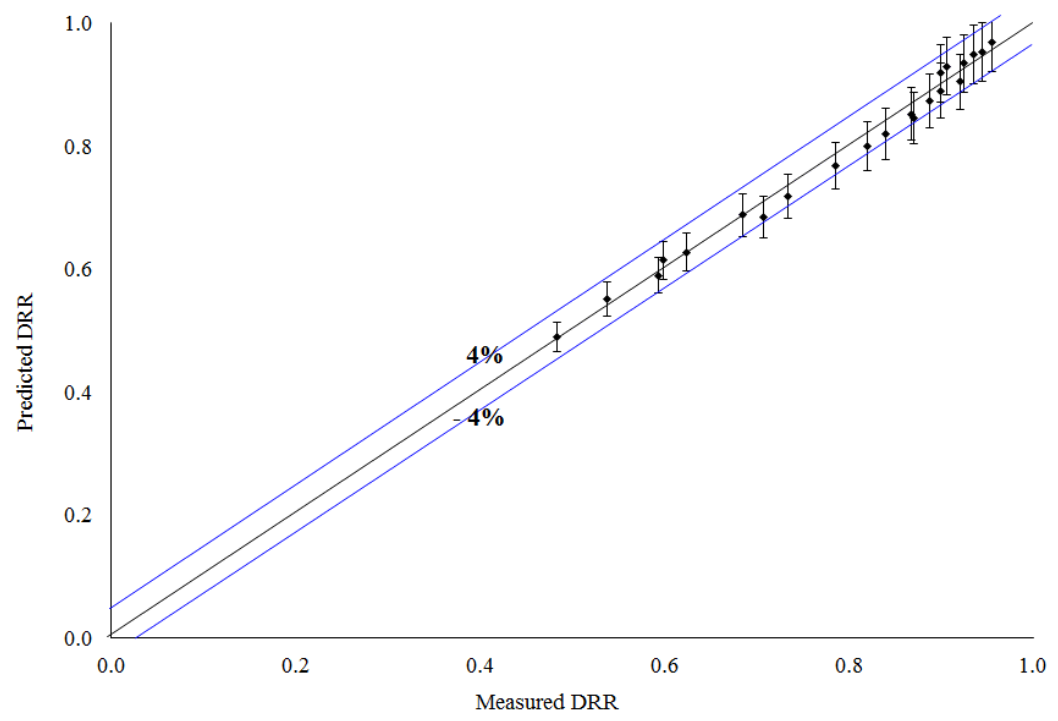

Figure 8. Cross Plot between Measured and Predicted DRR for ASP-820

\section{Theories and Discussion of Results}

Drag reduction is still not well understood. Several theories were proposed to explain this phenomenon, but none of them was able to give a definite explanation (Bewersdorff and Berman 1988; Sung et al. 2004). It is believed that the occurrence of drag reduction is related to shear thinning behavior (Frater 1967), viscoelasticity (Turner and Cats 1991), high extensional viscosity/shear viscosity ratios (Toonder et al. 1996), molecular stretching, decreased turbulence (Metzner and Park 1964), anisotropic viscosity, laminerization of turbulence, and vortex stretching (Myska and Stern 1994). Addition of salts and increasing the ionic strength causes polymer degradation, which results in decreasing its effectiveness as a drag reducer. Polymer in low ionic strength solutions exhibits considerable entanglements and complex branched appearance of the molecular structure, hence improving its performance (Molloy et al. 2000). As ionic strength increases, viscosity reduces and size and number of the large super-molecules reduce. Therefore, the polymer appears to be more rigid and less gel-like with a significant reduction in polymer entanglements (Myska and Zakin 1997). Furthermore, degree of polymer swelling decreases significantly as ionic strength of the solution increases. In high ionic strength solutions, positive ions shielding the negative ions, negate the repulsion and thus, result in decreasing the swelling. As a result, elastic forces decrease and performance of polymers as drag reducers is negatively 
affected (Shabrin 1974; Clifford and Sorbie 1985; Molloy et al., 2000).

Another important note is that, drag reduction performance of polymers is significantly affected by the ionic strength, and not by the salt concentration. Synthetic seawater, which contains three different salts: $\mathrm{Na}_{2} \mathrm{SO}_{4}, \mathrm{NaCl}$, and $\mathrm{CaCl}_{2}$, has TDS of 3.4\% lower than TDS of 4\% KCl test fluids. On the other hand, synthetic seawater has higher ionic strength of 0.6 compared to 0.53 for $4 \% \mathrm{KCl}$. Performance of both polymer is obviously interrelated to the ionic strength since both polymers exhibit a better drag reduction performance in $4 \% \mathrm{KCl}$ fluid with higher TDS, but lower ionic strength compared to synthetic seawater with lower TDS, but higher ionic strength. The drag reduction performance of the three fluids follows the same order where higher ionic strength solution yields lower drag reduction.

Furthermore, the adverse effects of salt and its ionic strength diminishes at higher Reynolds numbers. At higher Reynolds number, shear rate increases and promotes the polymer molecules to yield enhanced drag reduction. However, it is believed that after certain shear rate, molecules are negatively affected and degradation occurs. As a result, drag reduction minimizes.

Polymers exhibit different behaviors because of their nature, composition, molecular weight, molecular structure, etc. As seen in Figs. 1 through 6, ASP-700 polymeric solutions yield drag reduction higher than ASP-820 solutions. The maximum drag reduction of ASP-700 fresh water solution is $81 \%$ while it is $77 \%$ for ASP-820 in the same solution. Furthermore, effect of ionic strength on drag reduction characteristics of both polymers is diverse. ASP 700 is more resistant to degradation caused by increasing ionic strength, indicating that ASP-700 is more effective than ASP-820 in saline environment. This is mainly due to the different composition of these two polymers.

The anionic acrylamido-methyl propane sulfonate, AMPS ASP-700 is an analog of partially hydrolyzed polyacrylamide (PHPA), while ASP-820 is a sulfonate-containing polyacrylamide. Moreover, there are differences in molecular weight, polymer charge, and the associated hydrodynamic volume of the polymers. ASP-700 is less affected by the salinity of brines that contain divalent ions. This is in total synchronization with the viscosity data shown in Table 1. However, for all practical purposes, both fluids can be considered to exhibit excellent drag reduction characteristics.

\section{Conclusions}

1) ASP-700 and ASP-820 polymers yields a strong drag reduction performance behavior in both fresh water and brines. However, ASP-700 shows better drag reduction behavior.

2) Drag reduction characteristics of polymeric solution are significantly affected by the polymer type, molecular weight, molecular structure, shear rate, and salt content.

3) The presence of salts negatively affects drag reduction behavior of polymeric solutions. As the salt content increases, drag reduction behavior minimizes. However, these effects minimize as Reynolds numbers increase.

4) Ionic strength better correlates with drag reduction performance of polymer solutions, rather than salt type and/or concentration. As ionic strength increases, drag reduction decreases, even at low salt concentration.

5) Two equations relating drag reduction ratio with solutions ionic strength are proposed. The two correlations show an acceptable accuracy and are recommended for future investigation.

6) Future work is highly recommended to validate the proposed correlations, especially with different salt types and concentrations as well as data from large-scale flow loops.

\begin{tabular}{ll}
\multicolumn{2}{l}{ Nomenclature } \\
$C_{S}$ & salt concentration \\
$d$ & inside diameter of pipe \\
$D R$ & drag reduction \\
$D R_{o}$ & drag reduction for reference case (fresh water) \\
$D R R$ & drag reduction ratio \\
$D R_{S}$ & drag reduction for saline solvent \\
$f$ & Fanning friction factor \\
$f_{s}$ & Fanning friction factor of solvent \\
$f_{t}$ & Fanning friction factor of treated fluid \\
$I$ & ionic strength \\
$m$ & molality \\
$N_{R e}$ & Reynolds number
\end{tabular}




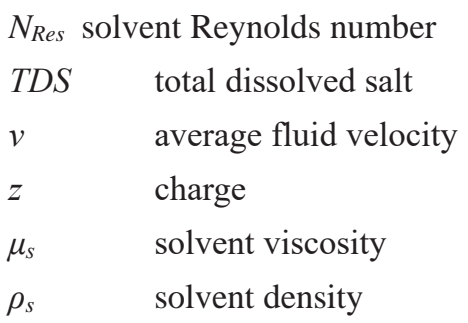

\section{References}

Al-Yaari, et al. (2013). Pressure Drop Reduction of Stable Emulsions: Role of Aqueous Phase Salinity. Presented at SPE Saudi Arabia Section Technical Symposium and Exhibition, Al-Khobar, Saudi Arabia, 19-22 May. SPE-168078-MS. Society of Petroleum Engineers. https://doi.org/10.2118/168078-MS.

Berman, N. S. (1978). Drag Reduction by Polymers. Annual Review: Fluid Mechanics, 10, 47-64.

Bewersdorff, H. W., \& Berman, N. S. (1988). The Influence of Flow-Induced Non-Newtonian Fluid Properties on Turbulent Drag Reduction. Rheological Acta, 27, 130-136. https://doi.org/10.1007/BF01331897.

Brunn, P. O. (1987). Some Modern Developments in the Flow of Dilute Polymer and Surfactant Solutions. PhysicoChemical Hydrodynamics, 8(4), 449-459.

Clifford, P. J., \& Sorbie, K. S. (1985). The effects of chemical degradation on polymer flooding. The International Symposium on Oilfield and Geothermal Chemistry, Phoenix, Arizona, April 9-11. https://doi.org/10.2118/13586.

Drew, T. B., Koo, E. C., McAdams, W. H. (1932). The friction factor for clean round pipes. AIChE, 28, 56-72.

Frater, K. R. (1967). Acoustic Streaming in an Elastic-Viscous Fluid. Journal of Fluid Mechanics, 30(22), 689-697. https://doi.org/10.1017/S0022112067001703.

Gasljevic, K., \& Matthys, E. F. (1996). Field Test of a Drag Reducing Surfactant Additive in the Hydronic Cooling System. Proc. ASME, Fluids Engineering Division (Publication) FED, San Diego, CA, USA. 237(2), 249-260. https://doi.org/10.1115/IMECE2004-62193.

Hassiba, K., \& Amani, M. (2013). The Effect of Salinity on the Rheological Properties of Water Based Mud under High Pressures and High Temperatures for Drilling Offshore and Deep Wells. Earth Science Research, 2, 175 - 186. https://doi.org/10.5539/esr.v2n1p175.

Hong. et al. (2015). Effect of Salt on Turbulent Drag Reduction of Xanthan Gum. Carbohydrate Polymers, 121, 342347. https://doi.org/10.1016/j.carbpol.2014.12.015.

Kamel, A., \& Shah, S. (2009). Investigation of Flow Behavior of Slick-Water in Large Straight and Coiled Tubing. Presented at SPE Hydraulic Fracturing Technology Conference, The Woodlands, TX, 19 - 21 January. Paper SPE-118949-MS. Society of Petroleum Engineers. https://doi.org/10.2118/118949-MS.

Lesieur, M. (1989). Turbulence. La Technique Moderne, 81(11-12), 37-40.

Lewis, G. N., \& Randall, M. J. (1921). The Activity Coefficient of Strong Electrolytes. Am. Chem. Soc., 1112-1154. https://doi.org/10.1021/ja01438a014.

Liu, Y., Gadde, P. B., \& Sharma, M. M., (2006). Proppant placement using reverse-hybrid fracs. Paper presented at the SPE Gas Technology Symposium, Calgary, Alberta, Canada, May 15-17. https://doi.org/10.2118/99580-PA.

Lumely, J. L. (1973). Drag Reduction in Turbulent Flow by Polymer Additives. Journal of Polymer Science, 7, 263-290. https://doi.org/10.1002/pol.1973.230070104.

Metzner, A. B., \& Park, M. G. (1964). Turbulent Flow Characteristics of Viscoelastic Fluids. Journal of Fluid Mechanics, 20(2), 291-303. https://doi.org/10.1017/S0022112064001215.

Molloy, P. J., Smith, M. J., \& Cowling, M. J. (2000). The effects of salinity and temperature on the behavior of polyacrylamide gels. Mater. Des., 21, 169-174. https://doi.org/10.1016/S0261-3069(99)00068-0. 
Myska, J., \& Stern, P. (1994). Properties of a Drag Reducing Micelle System. Colloid and Polymer Science, 272, 542-547. https://doi.org/10.1007/BF00653219.

Myska, J., \& Zakin, J. L. (1997). Differences in the Flow Behaviors of Polymeric and Cationic Surfactant Drag-Reducing Additives. Ind. Eng. Chem. Res., 36, 5483-5487. https://doi.org/10.1021/ie9703245.

Sastre de Vicente, M. (2004). The Concept of Ionic Strength Eighty Years after Its Introduction in Chemistry. Journal of Chemical Education, 81(5), 750 - 753. https://doi.org/10.1021/ed081p750.

Savins, J. G. (1964). Drag Reduction Characteristics of Solutions of Macromolecules in Turbulent Pipe Flow. Paper presented at the Meeting of AIChE, Houston, TX, 5-8 December. SPE 867. https://doi.org/10.2118/867-PA.

Shabrin, A. N. (1974). Investigation of the effect of temperature and salinity of solvent on reducing frictional drag in pipes by means of polymeric additives. Fluid Mech. Sov. Res., 3(1), 46-50.

Shah, S., \& Vyas, A. (2011). Temperature and Salinity Effects on Drag-Reduction Characteristics of Polymers in Coiled Tubing. SPE Production and Operation, 26(01), 55-66. Society of Petroleum Engineers. https://doi.org/10.2118/130685-PA.

Shah, S., \& Kamel, A. (2010). Investigation of Flow Behavior of Slick water in Large Straight and Coiled Tubing. SPE Production and Operation, 25 (01), 70 - 79. Society of Petroleum Engineers. https://doi.org/10.2118/118949-PA.

Sung, J. H. et al. (2004). Turbulent Drag Reduction Efficiency and Mechanical Degradation of Polyacrylamide. Journal of Macromolecular Science, B43 (2), 507-518. https://doi.org/10.1081/MB-120029784.

Toms, B. A. (1949). Some observations on the flow of linear polymer solutions through straight tubes at large Reynolds numbers. First Intl. Congress on Rheology, North Holland, Amsterdam, 135-145.

Toonder, J. M. J. et al. (1996). Drag Reduction by Polymer Additives in Turbulent Pipe Flow, Numerical and Laboratory Experiments. Journal of Fluid Mechanics, 337, 193-231. https://doi.org/10.1017/S0022112097004850.

Turner, M. S., \& Cates, M. E. (1991). Linear Viscoelasticity of Living Polymers. A Quantitative Probe of Chemical Relaxation Times. Langmuir, 7, 1590-1594. https://doi.org/10.1021/la00056a009.

Virk, P. S. (1975). Drag Reduction Fundamentals. AIChE Journal, 21 (4), 625-656. https://doi.org/10.1002/aic.690210402.

\section{Copyrights}

Copyright for this article is retained by the author(s), with first publication rights granted to the journal.

This is an open-access article distributed under the terms and conditions of the Creative Commons Attribution license (http://creativecommons.org/licenses/by/4.0/). 